\title{
A Three-Dimensional Numerical Simulation of a Great Plains Dryline
}

\author{
B. L. SHAW* \\ Air Force Institute of Technology, Wright-Patterson AFB, Ohio, and Department of Atmospheric Science, Colorado State University, \\ Fort Collins, Colorado \\ R. A. PIELKe \\ Department of Atmospheric Science, Colorado State University, Fort Collins, Colorado \\ C. L. ZIEGLER \\ National Severe Storms Laboratory, National Oceanic and Atmospheric Administration, Norman, Oklahoma
}

(Manuscript received 20 December 1995, in final form 25 September 1996)

ABSTRACT

\begin{abstract}
A three-dimensional, nonhydrostatic, nested grid version of the Colorado State University Regional Atmospheric Modeling System (RAMS) was used to perform simulations of an actual dryline that was observed as part of the COPS-91 field experiment on 15 May 1991. A control run designed to reproduce the observed conditions as accurately as possible was generated and verified against standard National Weather Service observations, PAM-II observations, M-CLASS soundings, and vertical cross-sectional analyses obtained from the NOAA P-3 aircraft. A representative heterogeneous soil moisture field for use in the control simulation was generated using an antecedent precipitation index (API). Representative vegetation coverage based on the USGS normalized difference vegetation index (NDVI) dataset was input into the model. An additional simulation using a homogeneous soil moisture field is compared to the control run.

Results of study indicate that the use of realistic heterogeneous soil moisture and vegetation may be extremely important for accurate prediction of dryline formation and morphology. The effect of variable soil moisture appears to be first order, with large impacts on the strength of the thermal and moisture gradients along the dryline, as well as its position, structure, and movement.
\end{abstract}

\section{Introduction}

\section{a. Purpose of research}

This paper presents a description and results of numerical simulations of a dryline that occurred over the southern Great Plains of the United States on 15 May 1991. The simulations were performed using a threedimensional, primitive equation, mesoscale model. The goal of these simulations was twofold: first, to glean as much insight as possible into the small to medium mesoscale structure and morphology of the dryline and the prestorm environment; and second, to explore the sensitivity of drylines to variations in the soil moisture and vegetation patterns.

*Current affiliation: Air Force Global Weather Center, Offutt AFB Nebraska.

Corresponding author address: Dr. Roger A. Pielke, Department of Atmospheric Science, Colorado State University, Fort Collins, CO 80523-1371.

E-mail: dallas@hercules.atmos.colostate.edu
The overall study has several primary objectives. First, by initializing the simulation with the same type of data readily available to operational models, this study shows the value added to numerical forecasts by realistic soil moisture and vegetation analyses. Second, the high-resolution, three-dimensional simulation provides insight into the processes by which drylines form and evolve. Third, the sensitivity simulations highlight the importance of the nonlinear interactions between the land surface and the atmosphere and how these interactions play a key role in defining boundary layer characteristics, which are important in determining convective potential. Finally, the simulations provide a basis for determining specific areas where research needs to be conducted to improve our understanding of drylines, land-atmosphere interactions, and methods of parameterizing these interactions in numerical weather prediction models.

The remainder of this section provides some background information on drylines and land surface influences on mesoscale weather. Section 2 describes the control simulation, including the meteorological conditions for the case study, the model used, and some 
key results of this simulation. Section 3 briefly describes some sensitivity studies and results of comparisons to the control simulation. The final section summarizes the results and conclusions and presents suggestions for future work.

\section{b. Drylines}

The term "dryline," apparently first coined by McGuire (1962), refers to a narrow zone containing a sharp gradient of moisture in the planetary boundary layer. The sharpness of the dewpoint gradient has been documented by several observational studies (e.g., NSSP Staff 1963; Parsons et al. 1991; Ziegler and Hane 1993; Hane et al. 1993) to be up to several degrees Celsius per kilometer, which is much larger than the May climatological average of $0.04^{\circ} \mathrm{C} \mathrm{km}^{-1}$ for this region (Dodd 1965). A comprehensive summary of dryline characteristics can be found in Schaefer (1986).

Numerical studies by Sun and Wu (1992) found essential ingredients for the formation of drylines. They concluded that the three most important factors in dryline formation and sustenance of the moisture gradient are the presence of low-level vertical wind shear, the sloping terrain, and a gradient in soil moisture. With these three features present, an initial gradient of atmospheric moisture was not a requirement for the generation of a dryline. These findings regarding the impact of shear and soil moisture were confirmed by Ziegler et al. (1995); terrain also played an important role in that study.

However, there are still questions as to exactly how these components work together to create the strong moisture gradient, convergence, and vertical motions along the dryline. One possible explanation is the solenoidal forcing mechanism (Sun and Ogura 1979; Sun and $\mathrm{Wu}$ 1992; Ziegler and Hane 1993; Ziegler et al. 1995). This explanation requires that a persistent gradient in virtual potential temperature exist in the vicinity of the dryline with cooler air to the east.

Many studies have found virtual potential temperature gradients in conjunction with drylines (Ziegler and Hane 1993; Ogura and Chen 1977). Ogura and Chen (1977) argued that this gradient contributed to the rapid increase of convergence due to the "inland sea-breeze" effect (sea breezes are discussed in Estoque 1962; Pielke 1974). Numerical studies (e.g., Anthes et al. 1982; Benjamin 1986; Benjamin and Carlson 1986; Sun and Wu 1992; Ziegler et al. 1995) have also supported the notion that this solenoidal mechanism is responsible for generating convergence and hence increasing the moisture gradient and vertical motion along the dryline.

On the other hand, while investigating this problem with high-resolution, two-dimensional numerical simulations, the results of Ziegler et al. (1995) showed no direct correlation between the peak updraft strength and the virtual potential temperature gradient at the dryline. Instead, they argued that the gradient of mean boundary layer virtual temperature east of the dryline results in a mesoscale hydrostatic pressure gradient. This causes an upslope flow to develop, which terminates abruptly at the dryline, focusing convergence and vertical motion at this location. This process then leads to increased thermal contrasts across the dryline by kinematic frontogenetic forcing, and ultimately to increased circulation and vertical motion via the solenoidal mechanism.

This paper hypothesizes that an east-to-west gradient of decreasing soil moisture can enhance the virtual potential temperature gradient by providing a source of moisture flux to the atmosphere in addition to the moisture being advected from the Gulf of Mexico. This enhanced gradient of virtual potential temperature in the boundary layer increases the kinematic frontogenetic forcing, resulting in the intense convergence, large moisture gradients, and strong vertical motions associated with classical drylines.

\section{c. Significance of heterogeneous soil moisture and vegetation}

Pielke and Segal (1986) showed that mesoscale circulations due to differential heating of the terrain can be significant. The principal method for creating differential heating is through heterogeneous surface characteristics. There has been much effort in recent years to include land surface information in numerical models, from microscale simulations through large-scale climate simulations (e.g., Avissar and Pielke 1989; Li and Avissar 1994; Kosta and Suarez 1992; Bonan et al. 1993; Pleim and Xiu 1995; Pitman 1994). This work has focused on issues such as the effect of land use on regional climate (e.g., Avissar and Pielke 1989; Pielke and Avissar 1990; Anthes 1984; Yan and Anthes 1988; Garrett 1982) and the improvement of numerical simulations for prediction purposes (Lee 1992; Pielke et al. 1997; Smith et al. 1994). Other studies suggested that the soil moisture field may be the most important parameter in determining the structure of the daytime boundary layer (e.g., McCumber and Pielke 1981; Zhang and Anthes 1982; Segal et al. 1995). Furthermore, Chang and Wetzel (1991) argued that the proper representation of evaporation and transpiration processes from the soil through vegetation canopies into the atmosphere is essential to mesoscale models, which try to predict prestorm environments.

In a study similar to ours, Lanicci et al. (1987) presented results of three-dimensional simulations performed using The Pennsylvania State University-National Center for Atmospheric Research (NCAR) regional model at coarse resolution. In their work, they also performed sensitivity tests on the dryline by comparing a control run which used a climatologically derived soil moisture distribution to several runs with perturbed soil moisture fields. They found that variations in soil moisture have a significant effect on the largescale dryline environment. 


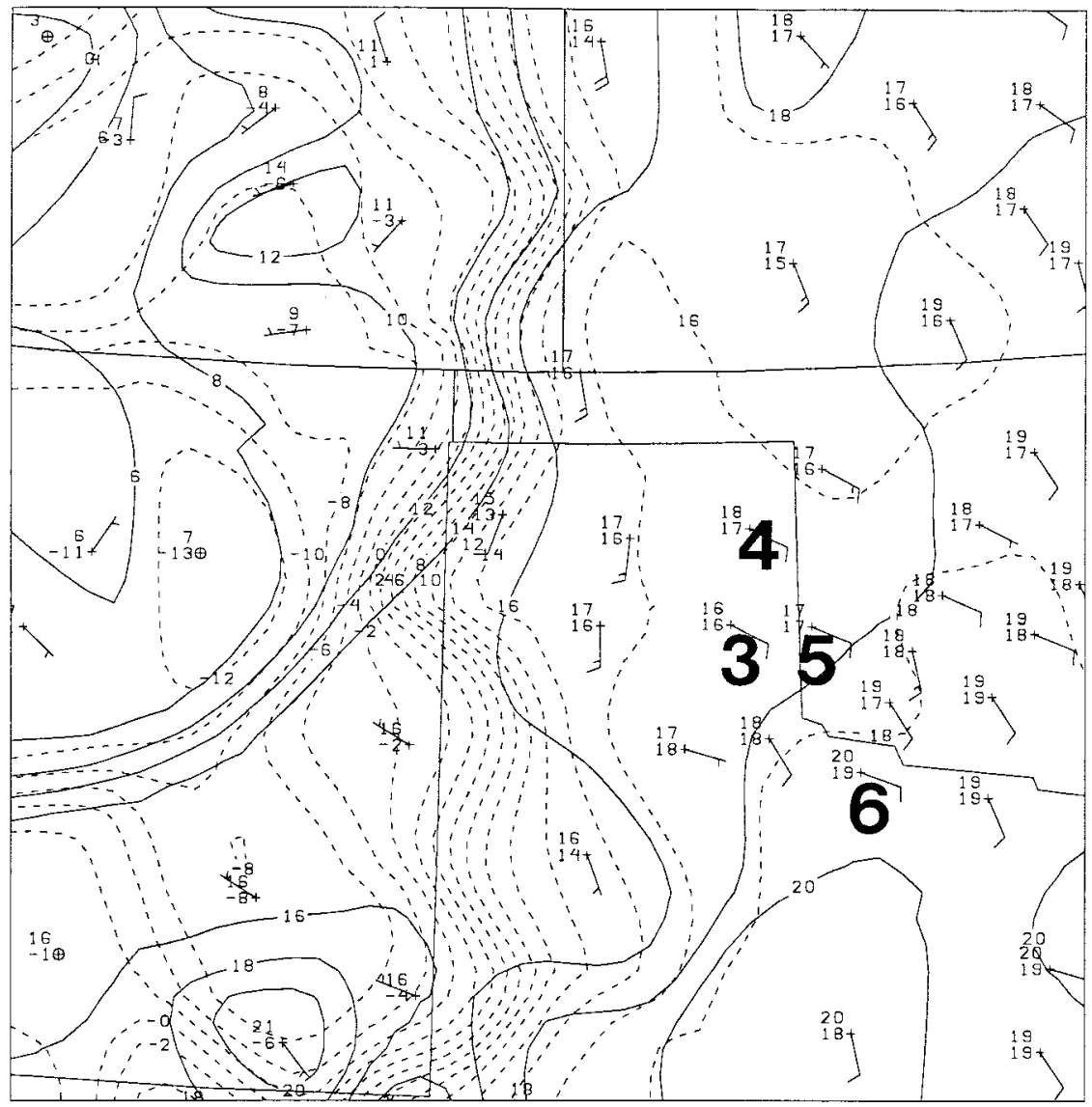

FIG. 1. Station plots and objective analysis of temperature and dewpoint $\left({ }^{\circ} \mathrm{C}\right)$ for $1200 \mathrm{UTC}$ 15 May 1991. Wind barbs are in knots. Contour interval is $2^{\circ} \mathrm{C}$. Data obtained from NWS and PAM-II observations available through NCAR. Numbered stations denote PAM-II locations discussed later in the text.

Ziegler et al. (1995) supported the findings of Lanicci et al. (1987) when they performed two-dimensional, high-resolution simulations of a dryline and compared their results with special airborne and sounding observations. Their study addressed the impact of east-west soil moisture variability and vegetation on the evolution of the convective boundary layer (CBL) and dryline formation. For classical dryline formation to occur in their simulations, a west-to-east gradient in volumetric soil moisture fraction of $0.15(50 \mathrm{~km})^{-1}$ was required. Without soil moisture gradients, they observed the formation of a "nonclassical" dryline, with strong convergence and updrafts collocated with a weak moisture gradient.

The research presented here expands on the work of Ziegler et al. (1995) by incorporating a three dimensional model and realistic soil moisture and vegetation distributions. It also improves upon the work performed by Lannici et al. (1987) by utilizing a much finer grid, more spatially detailed vegetation distributions, and a more representative soil moisture distribution to resolve some of the finescale features.

\section{The control simulation (CONT)}

a. Observed synoptic meteorological conditions on 15 May 1991

The particular dryline that serves as the focus of this study was observed as part of the COPS-91 field experiment (Hane et al. 1993). In addition to standard hourly National Weather Service (NWS) surface observations, data were also collected by the PAM-II (Portable Automated Mesonet II) network (Brock et al. 1986), M-CLASS (mobile Cross-chain Loran Atmospheric Sounding System) sounding units (Rust et al. 1990), and the NOAA P-3 research aircraft. Data collection schemes employed on this day are described in Hane et al. (1993).

All of the analyses of the observations shown in this section include data obtained from both the NWS standard network and the PAM-II network. Figure 1 shows the surface temperature and dewpoint analyses for 1200 UTC 15 May 1991. This corresponds to the initialization time for all of the simulations. A rather diffuse dewpoint gradient occurring from eastern Colorado south along 

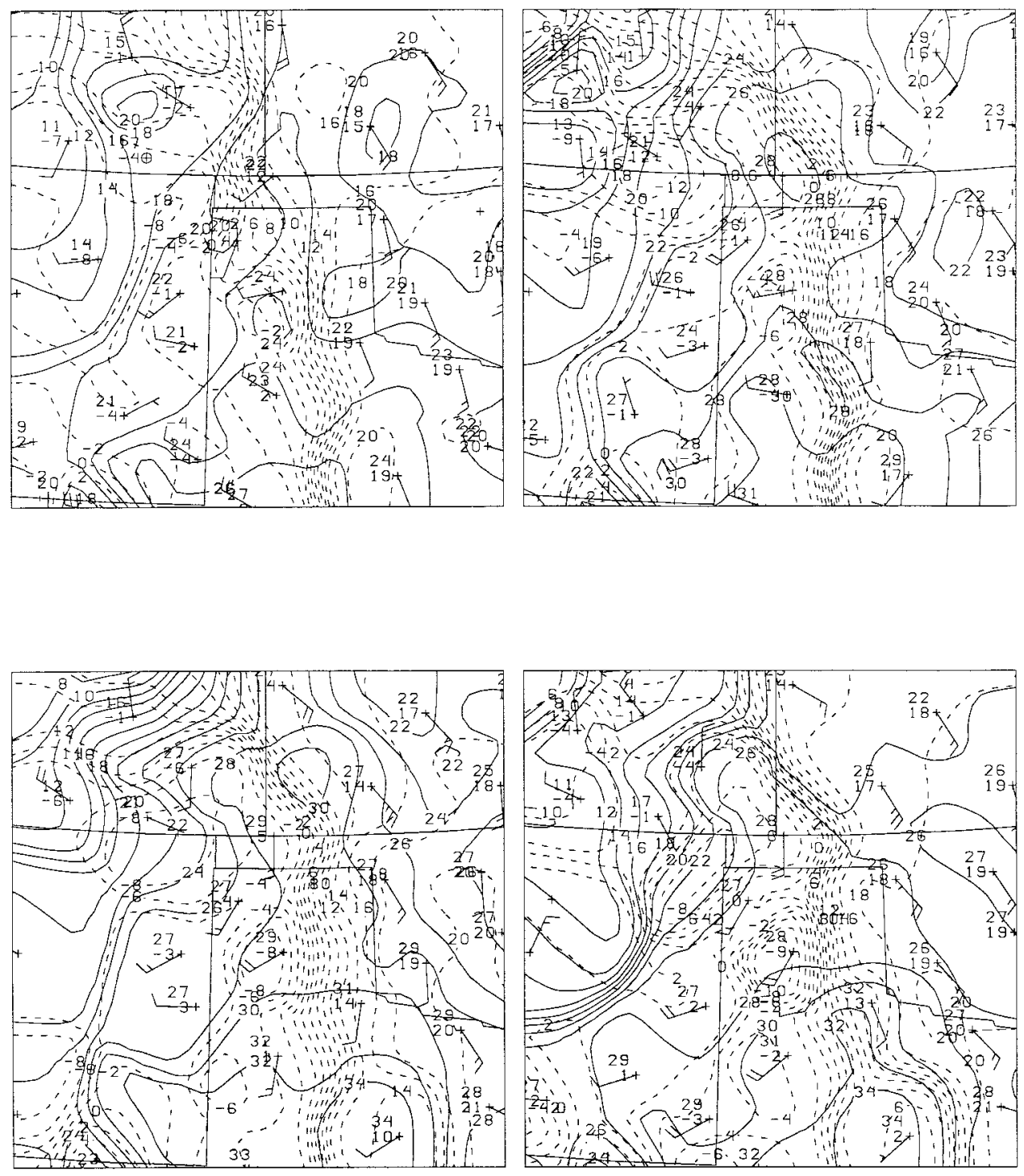

FIG. 2. Same as Fig. 1 but for 1500 UTC (top left), 1800 UTC (top right), 2100 UTC (bottom left), and 0000 UTC (bottom right). Data obtained from NWS and PAM-II observations available through NCAR. Station models are plotted for NWS sites only.

the Texas-New Mexico border was present at this time. Dewpoints were relatively constant east of this zone, with values ranging from $16^{\circ}$ to $19^{\circ} \mathrm{C}$ across the Texas panhandle and western Oklahoma. West of the dryline, dewpoint temperatures ranged from $-3^{\circ}$ to $-13^{\circ} \mathrm{C}$ across New Mexico and Colorado. Winds east of the moisture gradient were generally southerly or southeasterly. Westerly winds were observed west of the dewpoint gradient.

Figure 2 shows the temperature and dewpoint analyses for 1500 through 0000 UTC. By 1500 UTC, the southern half of the dryline had already moved nearly $100 \mathrm{~km}$ east to the central Texas panhandle. A zone of confluent winds along the moisture gradient had also become more pronounced, with southeasterly winds to the east and west-southwesterly winds to the west. A distinct tongue of warm air was analyzed just to the west of the confluent zone. Temperatures in the western Texas panhandle had risen rapidly to around $24^{\circ} \mathrm{C}$, while the temperatures in the eastern Texas panhandle and western Oklahoma continued to hover around $20^{\circ} \mathrm{C}$. Also note the pocket of slightly cooler air analyzed over the east-central Texas panhandle and southwest Oklahoma.

By 1800 UTC, the entire dryline was becoming very distinct from southwest Kansas south through the central Texas panhandle. The dewpoint temperatures varied by nearly $20^{\circ} \mathrm{C}$ across the Texas panhandle. The thermal tongue persisted, providing the typical dryline scenario of warm temperatures to the west and cooler tempera- 
tures to the east. Throughout the remainder of the afternoon, the location of the dryline remained nearly stationary as the moisture gradient continued to increase.

It is important to point out that the objective analyses shown do not capture the actual finescale structure of the moisture gradient due to coarse observational spacing and to spatial filtering due to the interpolation of data to the analysis grid. Aircraft and M-CLASS sounding information revealed that, in contrast with the analyses shown here, the moisture gradient along the dryline actually occurred on a scale of less than $30 \mathrm{~km}$, which is consistent with many of the dryline studies mentioned in the previous section and the model results of this study.

Since the region was only weakly influenced by upper-air disturbances on this particular day, convection was probably locally forced by convergence at the dryline generated by the thermally driven secondary circulation. Moderate convection developed in the immediate vicinity of the dryline. Deep convective clouds began developing between 1930 and 2000 UTC, with the deepest convection along the northern section of the dryline in southwest Kansas. By 2300 UTC, a few convective storms had developed in the eastern Texas panhandle and had begun moving northeast. Two of the storms that developed along the dryline eventually produced tornadoes near Laverne, Oklahoma, and Shamrock, Texas, that evening. Another study of the 15 May case by Grasso (1996) has explored the development of strong vertical rotation in simulated dryline convection.

\section{b. Model configuration}

The model employed for this study was the Colorado State University Regional Atmospheric Modeling System (CSU-RAMS, hereafter referred to as RAMS) described by Pielke et al. (1992) and Nicholls et al. (1995). RAMS has been validated as a forecast tool for various types of weather (e.g., Cram and Pielke 1987; Lyons et al. 1988; Cram et al. 1992; Cotton et al. 1994). For this study, it was configured as a three-dimensional, nonhydrostatic, compressible, primitive equation model. Surface-layer fluxes were parameterized using a prognostic soil model (Tremback and Kessler 1985) and vegetation model (Avissar and Pielke 1989). Vegetation parameters such as albedo, roughness length, and leaf area index $(\mathrm{LAI})^{1}$ were specified based on the vegetation type in the model. Vegetation type (or land-surface category) was specified as one of 18 possible values based on the Biosphere-Atmosphere Transfer Scheme (BATS; Dickinson et al. 1986). Turbulence and diffusion parameterizations were handled using the Smagorinsky deformation $K$ method with a dependence on the local Richardson number. No convective parameterizations were

${ }^{1}$ LAI is defined as from the top side of the leaves. employed; however, a microphysical parameterization for warm rainwater formation was used where the number concentration of raindrops is diagnosed from the prognosed mixing ratio and a specified droplet diameter.

To resolve some of the finer-scale features of the dryline environment, a nested grid configuration was used. The coarse outer grid used a grid spacing of $60 \mathrm{~km}$, with grids two and three using 20 and $5 \mathrm{~km}$, respectively. Vertical spacing ranged from $100 \mathrm{~m}$ at the lowest level to a maximum of $1000 \mathrm{~m}$ using vertical stretching. The vertical domain used 40 grid points and reached to approximately $18 \mathrm{~km}$ above the surface. A more detailed description of the model configuration can be found in Shaw (1995).

\section{c. Initialization}

Atmospheric variables were initialized using a combination of gridded $2.5^{\circ} \mathrm{NMC}$ pressure data, upper-air soundings, and surface observations for 1200 and 0000 UTC. The data were obtained from the mass storage system at NCAR. Lateral boundary conditions for the outer five grid points on the coarse grid were provided by a linear time series created from the data mentioned above ("nudging").

Topography, vegetation type, land percentage, and sea surface temperature were read onto the grids from USGS datasets, which have been configured for use in RAMS. A plot of the topography and vegetation type on the fine grid is shown in Fig. 3. For this simulation, the vegetation types on grid 3 were crop/mixed farming $(\mathrm{CMF})$, short grass (SG), evergreen needle leaf tree (ENT), irrigated crops (IC), and evergreen shrub (ES).

As mentioned earlier, LAI is a function of the vegetation type in the model. It is also a function of the seasonal average surface temperature. During the month of May, the vegetation in the Great Plains is near maximum "greenness," so the LAI is also approaching a maximum. Using this scheme, the value of maximum LAI for all vegetation types other than short grass, which has a maximum value of 2 , is 6 . Preliminary tests showed surface fluxes were much higher than what one would expect, based on measurements of surface fluxes for similar conditions (e.g., Stull 1988). In Avissar and Pielke (1989), the contribution to the surface fluxes by the vegetation canopy is directly proportional to the LAI. The value used to compute the heat fluxes uses LAI values multiplied by two to account for a contribution from both sides of the leaves.

During the study, it was questioned whether the values of LAI specified in BATS were appropriate, and if the simple linear relationship between LAI and the vegetation contribution to the turbulent fluxes used in our vegetation parameterization (Avissar and Pielke 1989) were appropriate. As discussed in the next two paragraphs, however, the LAI used in our experiments was limited to values that are consistent with observations 


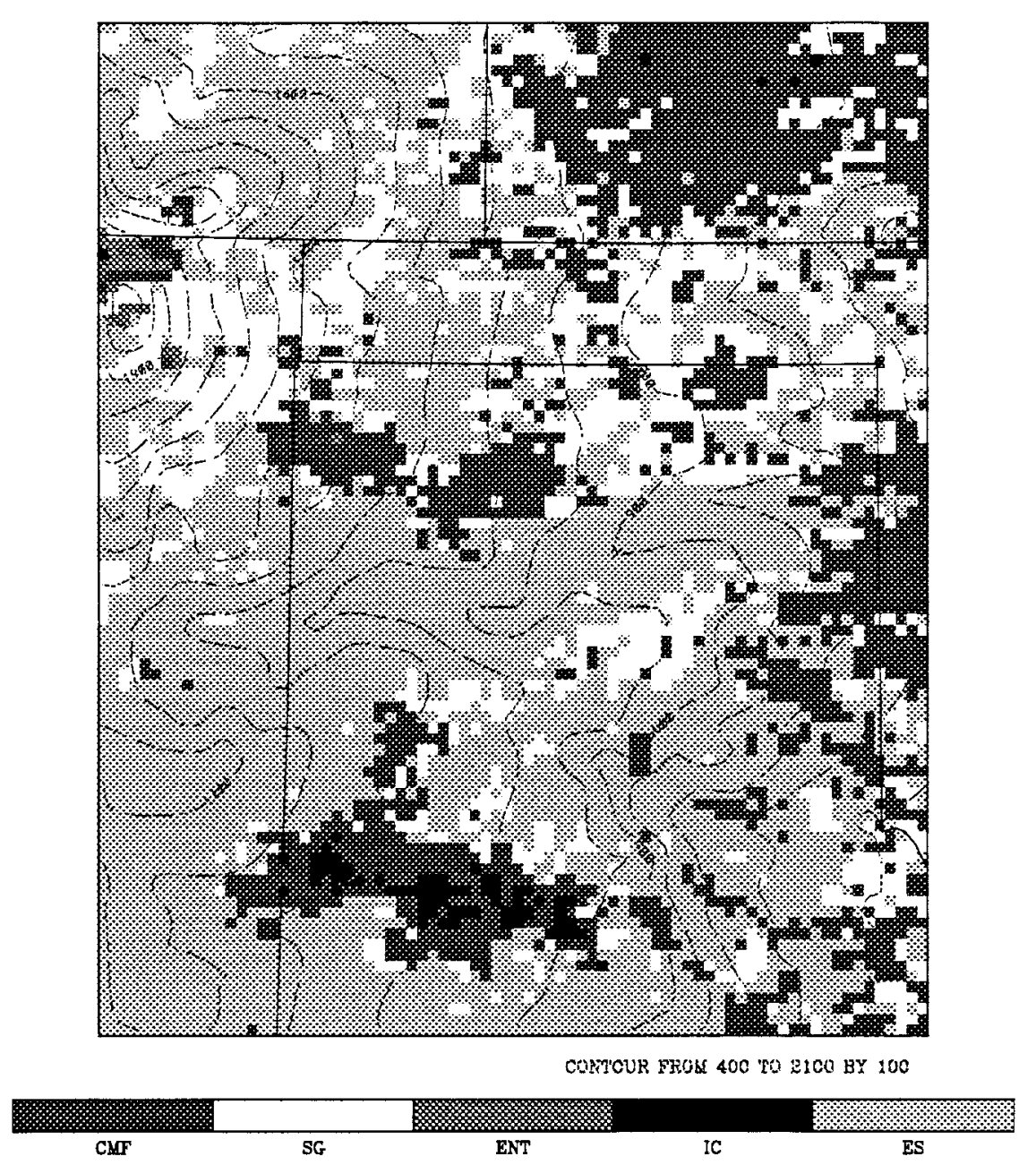

FIG. 3. Land cover and vegetation type from the Biosphere-Atmosphere Transfer Scheme (BATS; Dickinson et al. 1986) on grid 3. Vegetation types on this grid are crop/mixed farming (CMF), short grass (SG), evergreen needleleaf tree (ENT), irrigated crop (IC), and evergreen shrub (ES). Topographic contours are overlaid. Contour interval is $100 \mathrm{~m}$.

over our region of study. For this value of LAI, the simulated fluxes are very realistic.

Lee (1992) calculated LAI directly from normalized difference vegetation index (NDVI) data for the northern Great Plains for May 1990. Although the NDVI to LAI conversion formulas used by Lee do not cover all vegetation types, none of the LAI values calculated from the satellite data exceeded 2 anywhere on his grid. Although the actual leaf area may have LAIs as high as 6 or more, the amount of light reaching leaves at the bottom of the canopy will be greatly reduced in accordance with the Beer-Bouguer law (Rosenberg et al. 1983). This reduced flux density of light inside the canopy is expected to decrease transpiration by these inner leaves. Therefore, the "effective LAI" in terms of enhancing the surface flux was reduced in a model test run.

Lemeur and Rosenberg (1979) used their SHORTWAVE model to predict the reflectance of total short- wave, near-infrared, and photosynthetically active radiation (PAR) as a function of LAI and sun angle over a poplar forest. They concluded that the effect of LAI on transpiration is insignificant after a value of 2 is achieved. Based on these findings and the apparently unrealistically high fluxes, test runs were made with the LAI limited to 3 or less in the surface flux calculations. If the specified BATS vegetation type had an LAI exceeding 3 , the value was set to be equal to 3 . If the specified LAI value was less than or equal to 3 , then the actual value was used. This scheme produced realistic values of sensible and latent heat fluxes, and also produced modeled surface fields in reasonably good agreement with the observations of surface meteorological parameters. Thus, it was decided that the control simulation would employ the LAI modification to the RAMS code. A sensitivity test simulation that did not limit LAI (standard configuration) is described in Shaw (1995). 


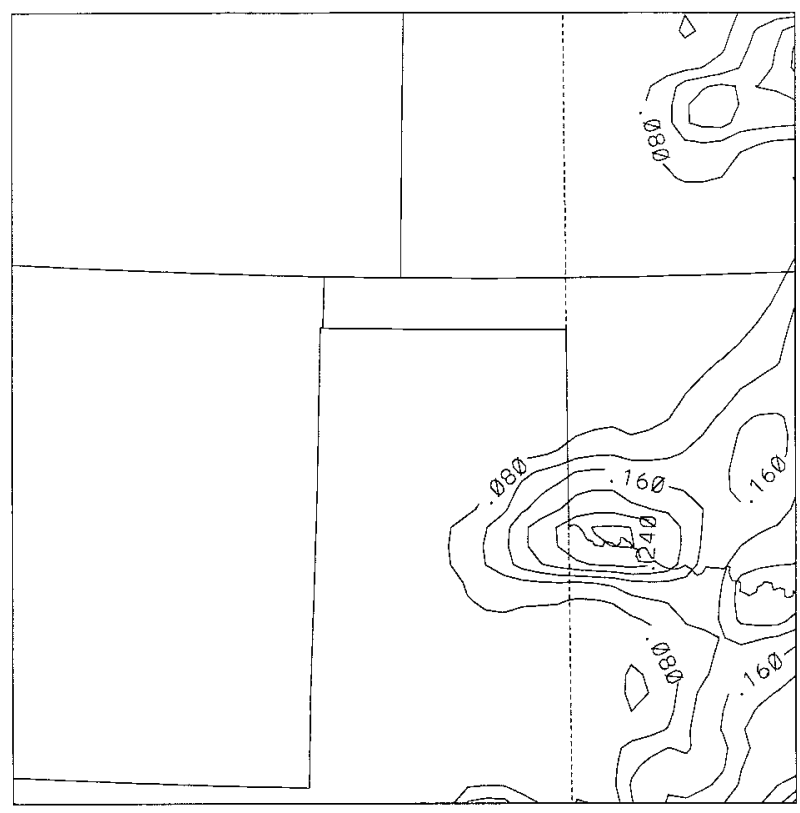

FIG. 4. Volumetric soil moisture distribution on grid 2 for the CONT simulation. Values represent fraction of total moisture capacity of the soil.

An antecedent precipitation index (API) was used to initialize the soil moisture for the control simulation (Wetzel and Chang 1988). An API value was calculated for each reporting station from a 3-month series of 24-h precipitation data and included a parameterization of bulk evaporation/transpiration. The API values were then converted into a value of volumetric soil moisture for sandy clay loam and objectively analyzed using a Barnes scheme. This analysis was then interpolated onto the RAMS grids. To ensure that the API was a realistic representation of the conditions, the analysis was con- firmed using qualitative comparisons to the weekly crop moisture index for 11 May 1991 (USDOC/USDA 1991). Figure 4 shows the volumetric soil moisture analysis on grid 2.

\section{d. Verification}

To lend credibility to any sensitivity tests, it is vitally important to show that the control simulation reasonably approximated the observed conditions. As shown in this section, the control run is realistic in depicting the location, orientation, and structure of the observed dryline.

In our discussion, results from the second grid were used for the horizontal plots, since for verification purposes the $20-\mathrm{km}$ grid spacing is broadly comparable to the finest surface station spacing. Additionally, the NWS and PAM-II observations were interpolated to a grid with identical coordinates and projection as the model's grid 2 and analyzed with a Barnes objective analysis. Figures 5 and 6 show a comparison of surface temperature and surface mixing ratio at 0000 UTC, respectively, with horizontal winds. As mentioned previously, the gradients of temperature and moisture as analyzed from the observations may not reflect the strength of the actual gradients due to coarse horizontal spacing of the observations.

The isotherm plots reveal that the control run simulated the pattern and magnitude of the dryline rather well. The position of the warm tongue over the Texas panhandle is correct, although the $28^{\circ} \mathrm{C}$ isotherm does not extend into the Oklahoma panhandle on the observation analysis as it does in the simulation. Note that there were stations reporting temperatures of $28^{\circ} \mathrm{C}$ in that region (see Fig. 2). The smoothing of the Barnes analysis scheme tends to miss narrow features when
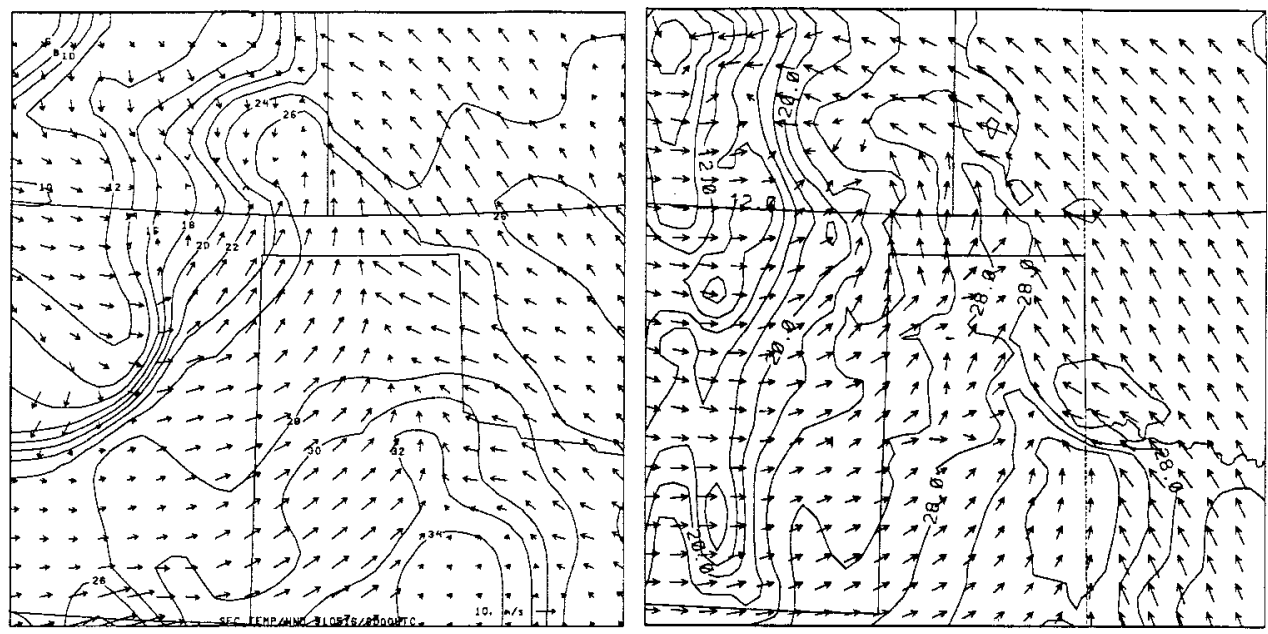

FIG. 5. Temperature (contour interval of $20^{\circ} \mathrm{C}$ ) and wind vectors as objectively analyzed from observations (left) and from the control simulation (right) at 0000 UTC 16 May 1991. A reference vector is included in the lower right corner of the left panel. 

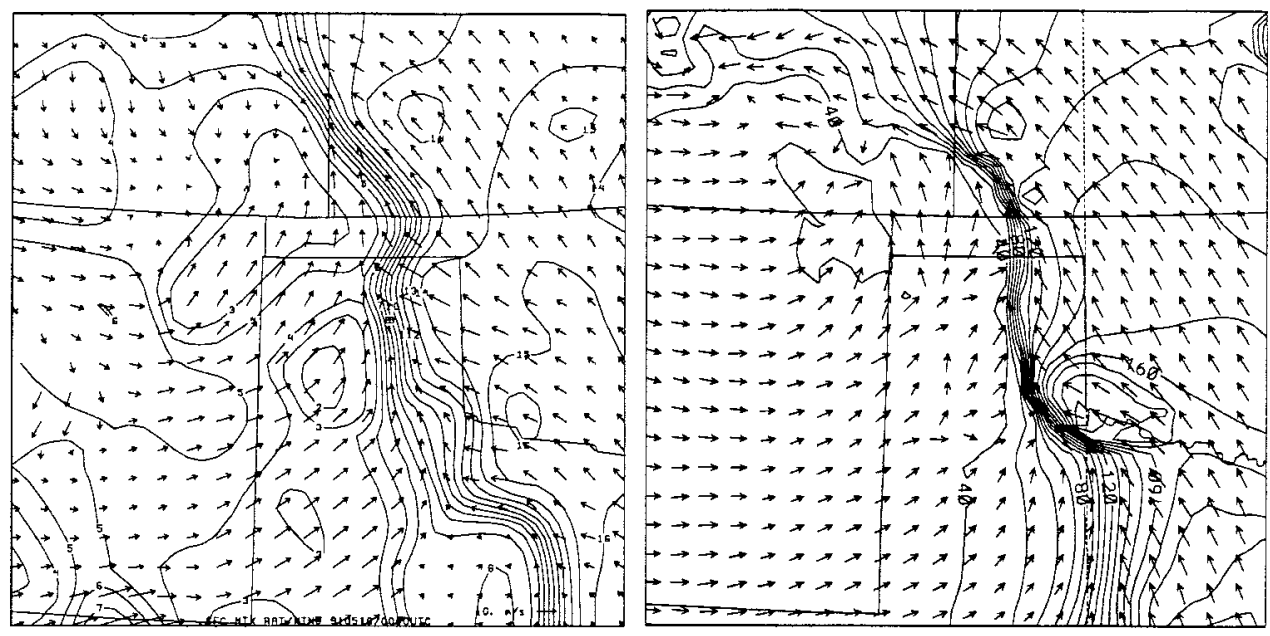

FIG. 6. Same as Fig. 5 but for water vapor mixing ratio (contour interval of $1 \mathrm{~g} \mathrm{~kg}^{-1}$ ).

observations are relatively sparse, and the model results seem to indicate that the zone of $28^{\circ} \mathrm{C}$ temperatures along the warm tongue was fairly narrow. The cool pocket of $26^{\circ} \mathrm{C}$ temperatures over southwest Oklahoma in the simulation does not appear as obvious on the analysis of the observations. However, if one again refers back to Fig. 2, there was a band of cooler temperatures $\left(26^{\circ} \mathrm{C}\right)$ extending northwestward from southwest Oklahoma.

Comparison of the surface mixing ratio fields also indicates the high quality representation of observed conditions by the control simulation. If one arbitrarily chooses the $7 \mathrm{~g} \mathrm{~kg}^{-1}$ isohume to represent the approximate location of the dryline, it is clear that the model closely reproduced the location and shape of the dryline. The peak moisture gradient in the simulation $\left(\approx 8 \mathrm{~g} \mathrm{~kg}^{-1}\right.$ per $20 \mathrm{~km}$ on grid 2) is much sharper than the objective analysis $\left(\sim 10 \mathrm{~g} \mathrm{~kg}^{-1}\right.$ per $\left.100 \mathrm{~km}\right)$. In actuality, based on the M-CLASS soundings and the aircraft traverses, the simulated moisture gradient was actually slightly less than the observed gradients exceeding $3 \mathrm{~g} \mathrm{~kg}^{-1}$ per $2 \mathrm{~km}(150 \mathrm{~m} \mathrm{AGL})$ and $6 \mathrm{~g} \mathrm{~kg}^{-1}$ per $3 \mathrm{~km}$ at $500 \mathrm{~m}$ AGL. If a finer grid were employed (e.g., 1-km spacing), we speculate that gradients as intense as those observed probably could be simulated. However, the simulation is still able to resolve features that could not have been observed from the standard data.

The main discrepancy in the simulation concerning the moisture field was that the model tended to be too moist just above the surface, both east and west of the dryline. The moist patch over southwest Oklahoma (which corresponded to a moist patch of soil) was 2-3 $\mathrm{g} \mathrm{kg}^{-1}$ too moist in the simulation and covered a larger area than the observations would indicate. Horizontal flow was divergent and a mesoscale surface pressure ridge (not shown) was in place over the moist patch, forcing the development of a nonclassical mesoscale circulation (NCMC; Segal and Arritt 1992). West of the dryline, the simulation results are very comparable to the observations with the exception of the west-central Texas panhandle where a patch of extremely dry air was apparent in the observations.

As with the surface temperatures and mixing ratios, the control run also simulated the winds with accuracy. The position of the circulation center associated with the low pressure system in southeast Colorado was predicted accurately, as well as the zone of confluent winds associated with the dryline. One important feature that appeared in both the observations and the control simulation is the zone of nearly easterly winds in extreme southwest Oklahoma extending about $50 \mathrm{~km}$ south into Texas. This area of strong ageostrophic easterly winds corresponded to the area of extremely moist soil in the model initialization. If these easterly winds are a result of solenoidal forcing induced by the soil moisture gradient, one might presume that the soil moisture analysis created by the API method was representative and that it was an important feature that affected the dryline environment.

Individual station information from both NWS and PAM-II sites, data collected from the P-3 traverses (not shown; e.g., see Fig. 2 of Hane et al. 1993), and M-CLASS soundings were also used to compare the observations with the model simulation. Figure 7 is a plot of the two M-CLASS soundings overlaid with plots of model output from the nearest points on grid 3 at 2300 UTC. The simulated soundings exhibited the classical features of the west and east dryline environments and strongly resembled the observed soundings for this particular case. The control run simulated the western temperature profile (MC1) with accuracy and was more moist than observations. East of the dryline at MC2, the control run closely approximated the observations, although the inversion above the moist boundary layer was at a lower altitude than observed. Additionally, the control run at MC2 was too moist in the lowest $50 \mathrm{mb}$, 

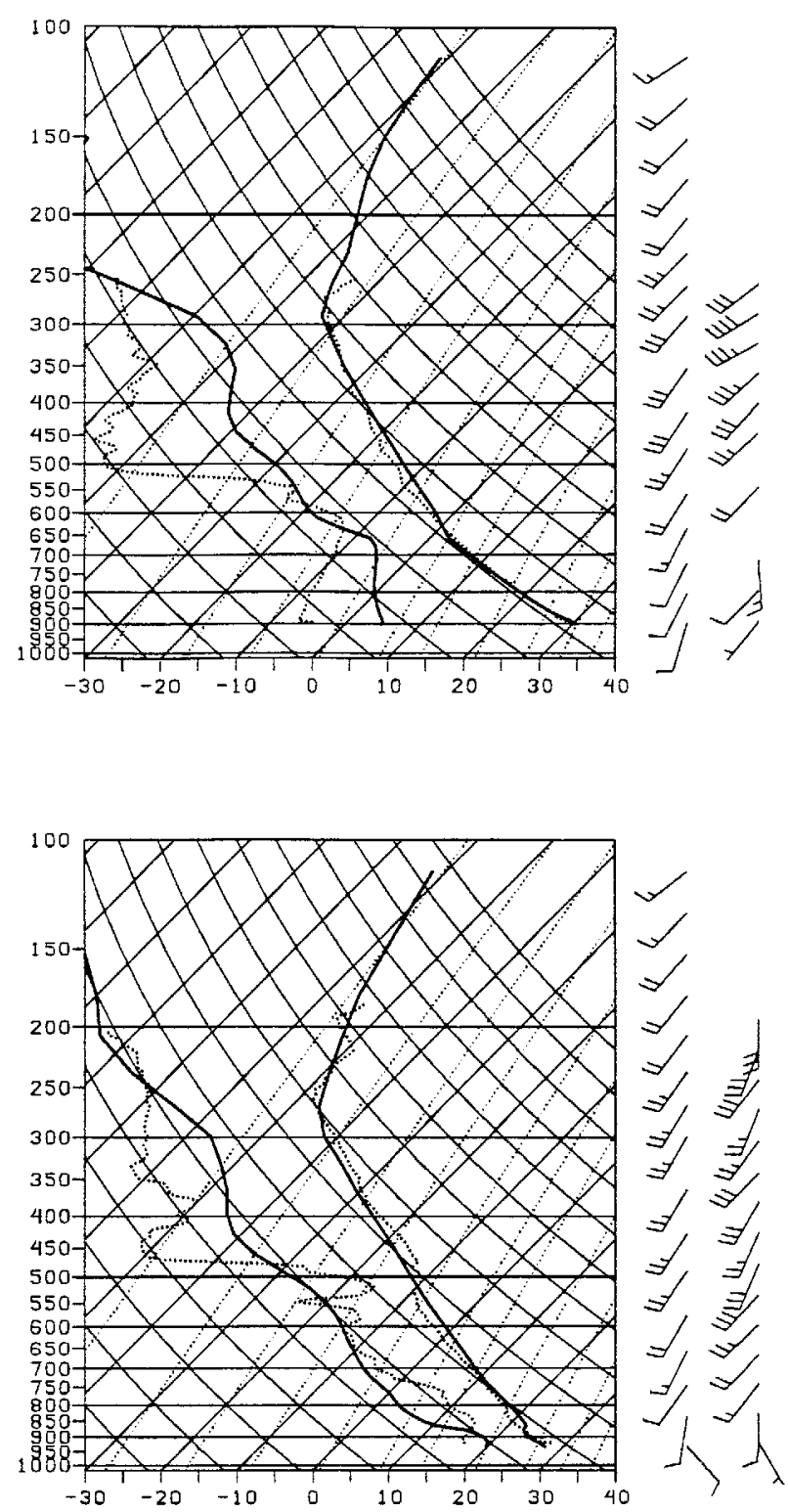

FIG. 7. Skew $T$ plots at MC1 (top) and MC2 (bottom), located just west and east of the dryline in the eastern Texas panhandle, respectively. Solid line profiles are from the nearest grid point in the control simulation. M-CLASS observed profiles are plotted with dotted lines. Left and right wind profiles are from the CONT run and observations, respectively, and are in meters per second. but was slightly too dry above this layer up to $475 \mathrm{mb}$, above which it was again too moist. However, the control simulation forecast of the moisture profile at the two M-CLASS sounding locations is still quite good with respect to the layer averages.

Various parameters calculated from the soundings are compared with observed values in Table 1. The thermodynamic indices were calculated based on an average of the lowest $1-\mathrm{km}$ conditions, approximately the observed convective boundary layer depth, to reduce the effect of surface-layer moisture bias on simulated sounding parameters. The storm-relative helicity (SREH) was calculated for the surface to 4-km layer. An estimated storm motion was calculated for each grid point by taking $75 \%$ of the mean $3-10-\mathrm{km}$ wind speed and adding $30^{\circ}$ to the mean direction [i.e., storm motion slightly to the right, as suggested by Wallace and Hobbs (1977)]. Observed and modeled sounding parameters show broad agreement and, in particular, reveal conditions capable of supporting rotating supercell thunderstorms east of the dryline.

Vertical cross sections were also taken from the model output and compared to cross sections derived from data taken during the P-3 flight and can be seen in Shaw (1995). The cross sections revealed that the simulated dryline was approximately $30 \mathrm{~km}$ west of the observed location along the P-3 track. The surface mixing ratio gradient was also slightly weaker than observed (about $0.1 \mathrm{~g} \mathrm{~kg}^{-1} \mathrm{~km}^{-1}$ lower), and the vertical motions at the dryline were slightly weaker in the simulation. Since the model resolution on grid 3 was effectively $10 \mathrm{~km}$, this performance is considered to be quite good.

One method that can be used to determine how well the model represented the partitioning of the sensible and latent heat fluxes is to construct a conserved variable diagram and interpret this using the saturation-point analysis technique (Betts 1982, 1984). Following Ziegler and Hane (1993), time series plots of mixing ratio versus potential temperature at the surface were plotted for several stations east and west of the dryline and compared to model results. These time series plots represent "mixing lines" whose slopes provide an indication of the Bowen ratio. Similar slopes between the modeled and observed mixing lines would indicate that the model provided a reasonable representation of the surface flux partitioning. An advantage of this method

TABLE 1. Comparison of observed and control simulation (CONT) sounding parameters for 2300 UTC 15 May 1991. Thermodynamic variables were calculated based on mean conditions of the lowest $1 \mathrm{~km}$. SREH is calculated from 0 to $4 \mathrm{~km}$.

\begin{tabular}{lcccrrr}
\hline \hline & $\begin{array}{c}\text { Mean } \\
\text { temperature for } \\
\text { lowest } 1 \mathrm{~km} \\
\left({ }^{\circ} \mathrm{C}\right)\end{array}$ & $\begin{array}{c}\text { Mean } \\
\text { mixing ratio } \\
\text { for lowest } 1 \mathrm{~km} \\
\left(\mathrm{~g} \mathrm{~kg}^{-1}\right)\end{array}$ & $\begin{array}{c}\text { Convective } \\
\text { temperature } \\
\left({ }^{\circ} \mathrm{C}\right)\end{array}$ & $\begin{array}{c}\text { Lifted index } \\
\left({ }^{\circ} \mathrm{C}\right)\end{array}$ & $\begin{array}{c}\mathrm{CAPE} \\
\left(\mathrm{J} \mathrm{kg}^{-1}\right)\end{array}$ & $\begin{array}{c}\text { SREH } \\
\left(\mathrm{m}^{2} \mathrm{~s}^{-2}\right)\end{array}$ \\
\hline Obs west & 23.7 & 2.6 & 30.6 & 1.9 & 0 & -6.5 \\
CONT west & 23.8 & 5.3 & 30.4 & -1.5 & 251 & 71.3 \\
Obs east & 21.7 & 12.4 & 29.1 & -6.9 & 1839 & 176.5 \\
CONT east & 22.9 & 10.9 & 30.7 & -6.5 & 1780 & 175.5 \\
\hline
\end{tabular}




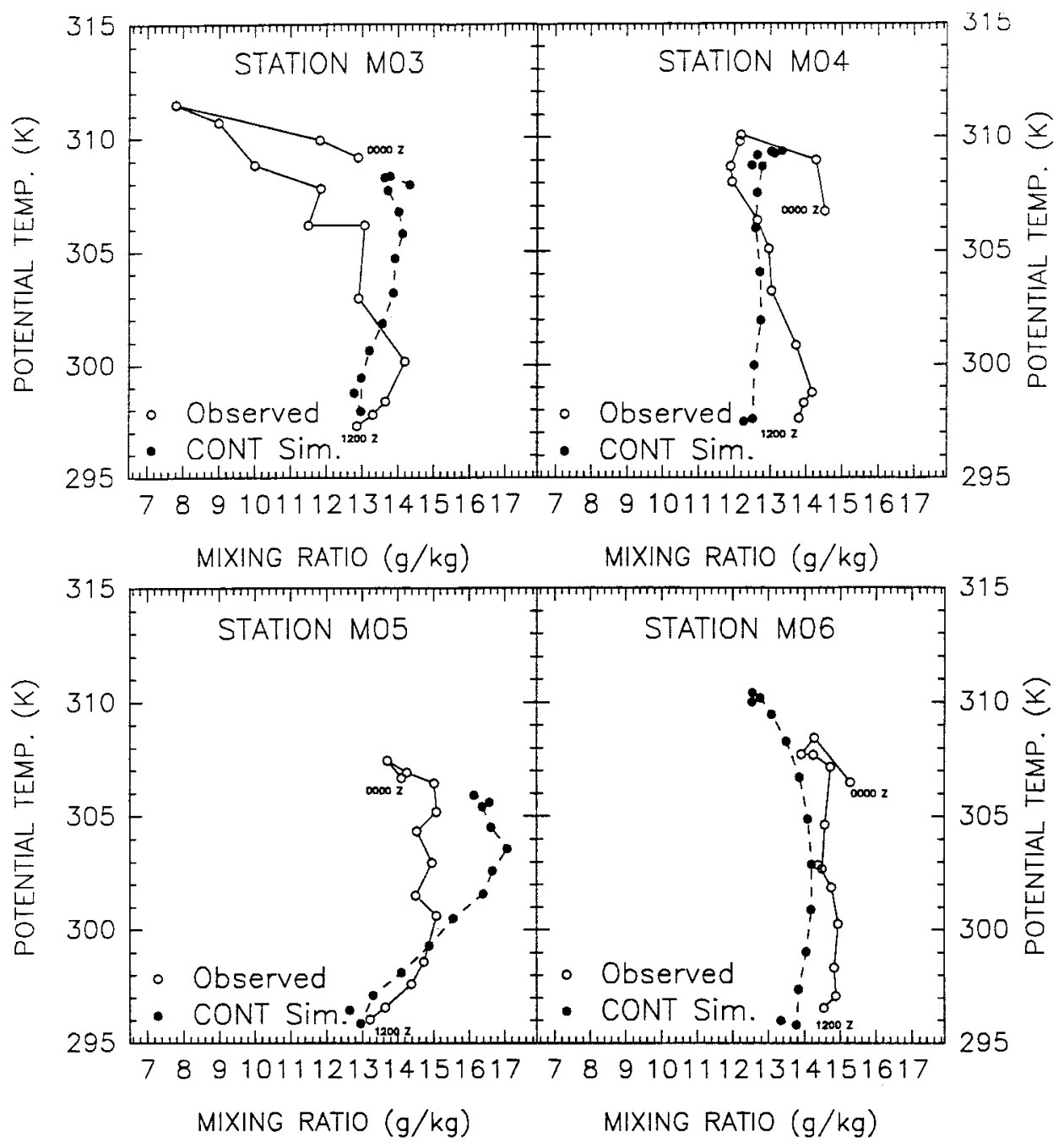

FIG. 8. Conserved variable time series diagrams for four observation sites east of the dryline comparing observations to model gridpoint data. All points are located in the eastern Texas panhandle and extreme western Oklahoma except M06, which was just southeast of Childress, Texas. Saturation points are hourly values, except at M03 where the 1656 UTC observation has been substituted for the missing 1700 UTC observation. Station locations are denoted in Fig. 1 (e.g., M03 is labeled 3 in Fig. 1).

is that it is relatively insensitive to differences between the model and observations at the initial time.

Figure 8 contains plots for four PAM-II stations located east of the dryline and corresponding plots from the nearest grid location in the control simulation. Again, in all cases except at station M06, the model results were slightly too moist. This difference is most pronounced at stations M03 and M05 in the late afternoon hours.

A comparison of the profile at M03 with the P-3 traverses, as in Shaw (1995), demonstrates that the dryline reached this station from the west around 2200 UTC, as entrainment drying occurred from 1500 to 2200 UTC. Some of the entrainment drying inferred from observations appears to have been offset by episodes of horizontal moisture transport (e.g., from 1600 to 1700 UTC). During a later episode of moisture influx from
2200 to 0000 UTC, it appears as if the dryline retreated back to the west of the station. There was a much weaker indication of warming and drying at this location in the control simulation, and the modeled drying occurred later in the day, from 1900 until 2200 UTC. It was pointed out earlier that the simulated dryline was approximately $30 \mathrm{~km}$ to the west of the observed location. This would probably account for the discrepancy at station M03, which apparently was just east of the dryline throughout the afternoon hours.

At M05, the model results showed moistening continuing until 2000 UTC, while the observation indicated a generally constant amount of moisture from 1600 until 2000 UTC. After 2000 UTC, the atmosphere warmed and dried until 2300 UTC, and the model captured this feature fairly accurately. The other two stations appear to have been modeled reasonably well. 
All four stations reflect characteristics of "moistening" or "entrainment-drying" convective boundary layers (Mahrt 1991), with the westernmost stations moving from the moistening to drying phase earlier than the easternmost stations. Since M06 is just upstream from the moist patch in southwest Oklahoma, while M05 is immediately downstream from the moist patch, differences in the timing and duration of the moistening stage at both sites is consistent with downstream flux of moisture transpired over the moist soil patch.

Similar plots were made for Dalhart and Amarillo (Shaw 1995), both of which were west of the dryline throughout most of the day. The mixing lines for both stations were prominently modeled, indicating the warming and drying trend that one would expect for locations west of the dryline. Strong entrainment warming and drying were evident at AMA from 1400 to 1500 UTC, indicative of dryline passage, but was not emphasized in the model, although a wind shift and diffuse moisture gradient was simulated. Inspection of P-3 data (not shown) indicates that the dryline was $15-30 \mathrm{~km}$ east of AMA around 1530 UTC. The strong drying observed at AMA from 1400 to 1500 UTC is indicative of the inversion east of the dryline being eroded.

Based on all of these qualitative comparisons of the control run to observations, as well as some quantitative comparisons (shown later), RAMS demonstrated a capability to reliably predict the evolution of the dryline for this particular case. This allows the results to be used for gaining insight into the dryline and prestorm environmental structure and for comparison to sensitivity tests.

\section{e. Simulated dryline environment}

A plot of the sensible and latent heat fluxes is shown in Fig. 9. The location of the moist patch of soil in southwest Oklahoma is very obvious on these plots. The sensible heat flux actually decreases to $0 \mathrm{~W} \mathrm{~m}^{-2}$ or less in this area, while the latent heat flux exceeds $400 \mathrm{~W}$ $\mathrm{m}^{-2}$ and approaches $500 \mathrm{~W} \mathrm{~m}^{-2}$. There is clearly a large variability of the simulated heat fluxes in the northsouth direction, producing an undulation of the dryline in the north-south direction (Fig. 6). The result is a gradient of sensible and latent heat fluxes with opposite signs of approximately $225 \mathrm{~W} \mathrm{~m}^{-2}(50 \mathrm{~km})^{-1}$ in the southern portion of the Texas panhandle. Although this heat flux gradient is about twice the value that Ziegler et al. (1995) determined to be required for dryline formation, the results of both studies are comparable since the value here is a peak value rather than a north-south average.

The strong gradient of latent heat flux probably contributed to the intensification of the atmospheric moisture gradient in this region. The strong sensible heating gradient provided a mechanism through which thermal gradients were produced, which may have induced mesoscale circulations in this region that worked to further
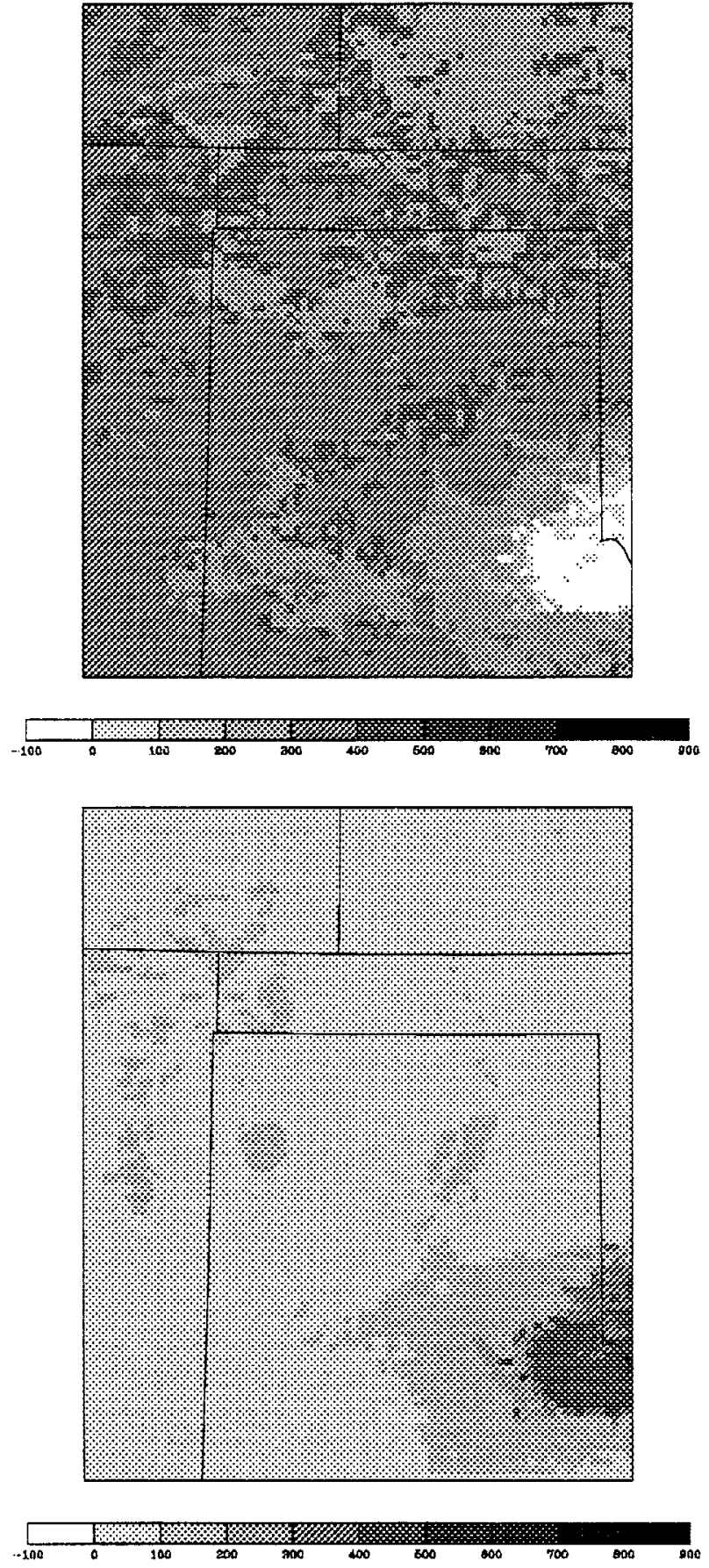

FIG. 9. The sensible (top) and latent (bottom) heat fluxes ( $\left.\mathrm{W} \mathrm{m}^{-2}\right)$ on grid 3 from the control run at 2000 UTC.

intensify the atmospheric gradients (Pielke and Segal 1986; Ziegler et al. 1995).

Strong gradients of temperature and moisture did exist in the area of the flux gradient in the observations and the simulation, indicating the role of differential heating to force locally high surface pressures and horizontal divergence over the moist patch. Additionally, 

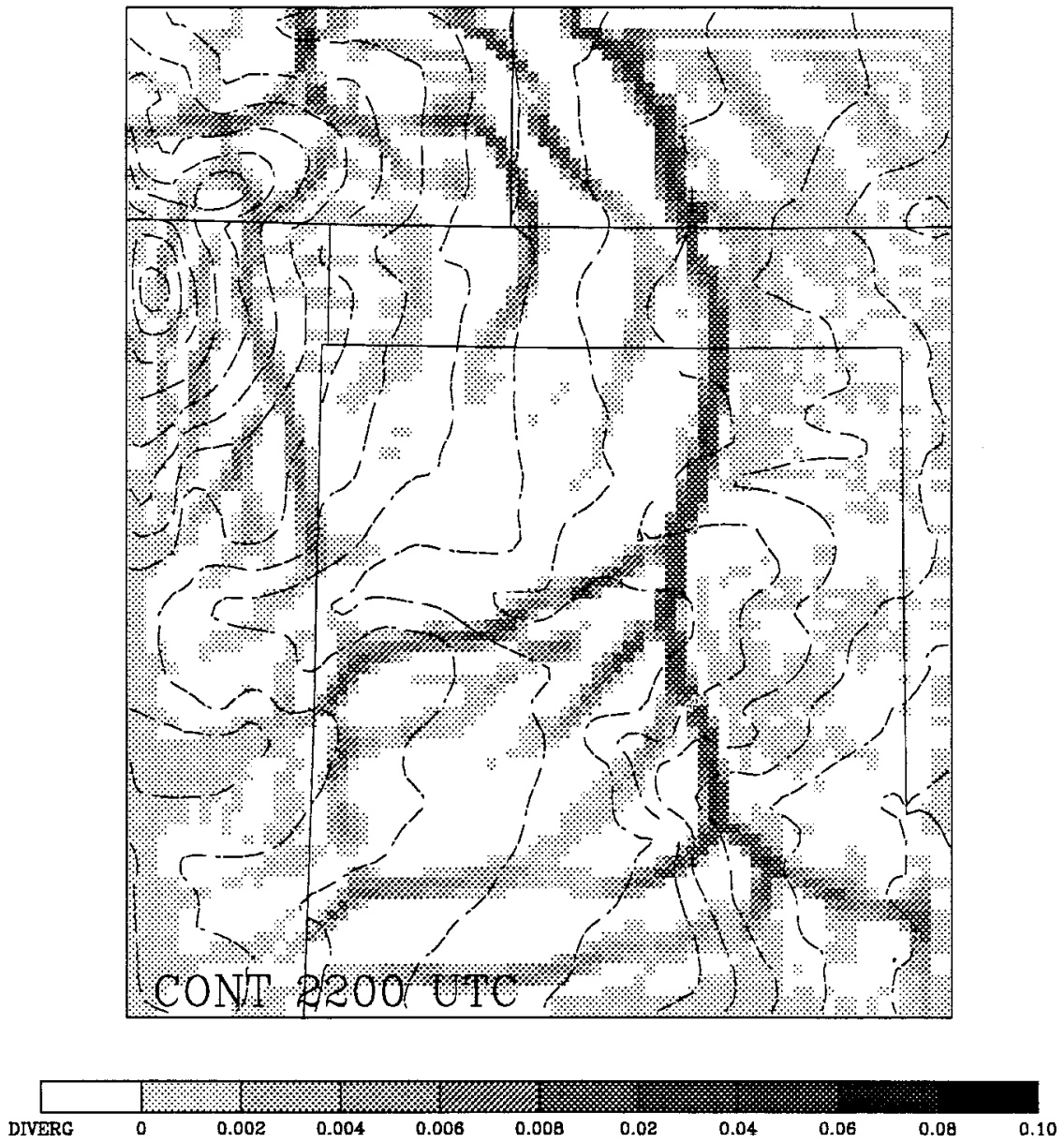

FIG. 10. Magnitude of horizontal moisture flux convergence $\left(\mathrm{g} \mathrm{kg}^{-1} \mathrm{~s}^{-1}\right)$ for the control simulation at 2200 UTC. Topographic contours $(\mathrm{m})$ are overlaid. Moisture divergence areas are white filled.

there was an area of winds with more of an easterly component just to the east of the flux gradient both in the observations and simulation.

The horizontal dryline structure as simulated in the control run is effectively illustrated in a plot of horizontal moisture flux convergence (Fig. 10). The dryline is very pronounced as a continuous band of extremely strong moisture convergence. The bands of convergence seen west of the dryline broadly resemble horizontal roll circulations. However, the model resolution used here is too coarse to represent the class of roll-type circulations known as horizontal convective rolls (HCRs), which are typical of a highly sheared, convectively unstable environment as present near the dryline. In any event, it is intriguing that these roll-like features appear to produce small-scale undulations where they intersect with the dryline, suggesting a connection to studies of "dryline wave" generation discussed by McGinley and Sasaki (1975) and Koch and McCarthy (1982). Although our inferences are based on model results, the present study documents these features in the dryline environment for the first time.

The analyses of vertical soundings generated from the simulation indicated that the environment east of the dryline was conducive to severe storm formation. Using the same calculation methods as described earlier, horizontal plots of CAPE and SREH were generated. Figure 11 shows the CAPE (convective available potential energy) field from the control simulation at 2000 UTC. Values of CAPE ranged from $0 \mathrm{~J} \mathrm{~kg}^{-1}$ west of the dryline to $3000 \mathrm{~J} \mathrm{~kg}^{-1}$ east of the dryline, with the highest values over the moist soil patch and at the eastern edge of the grid, where low-level atmospheric moisture was abundant. A very tight gradient (including local maxima) of CAPE existed along the dryline.

The SREH at 2000 UTC is shown in Fig. 12 for all points where CAPE exceeded $500 \mathrm{~J} \mathrm{~kg}^{-1}$. An assumed storm motion was calculated for each grid point and was taken to be $75 \%$ of the speed and $30^{\circ}$ to the right of the mean wind from 3 to $10 \mathrm{~km}$. As with the CAPE, 

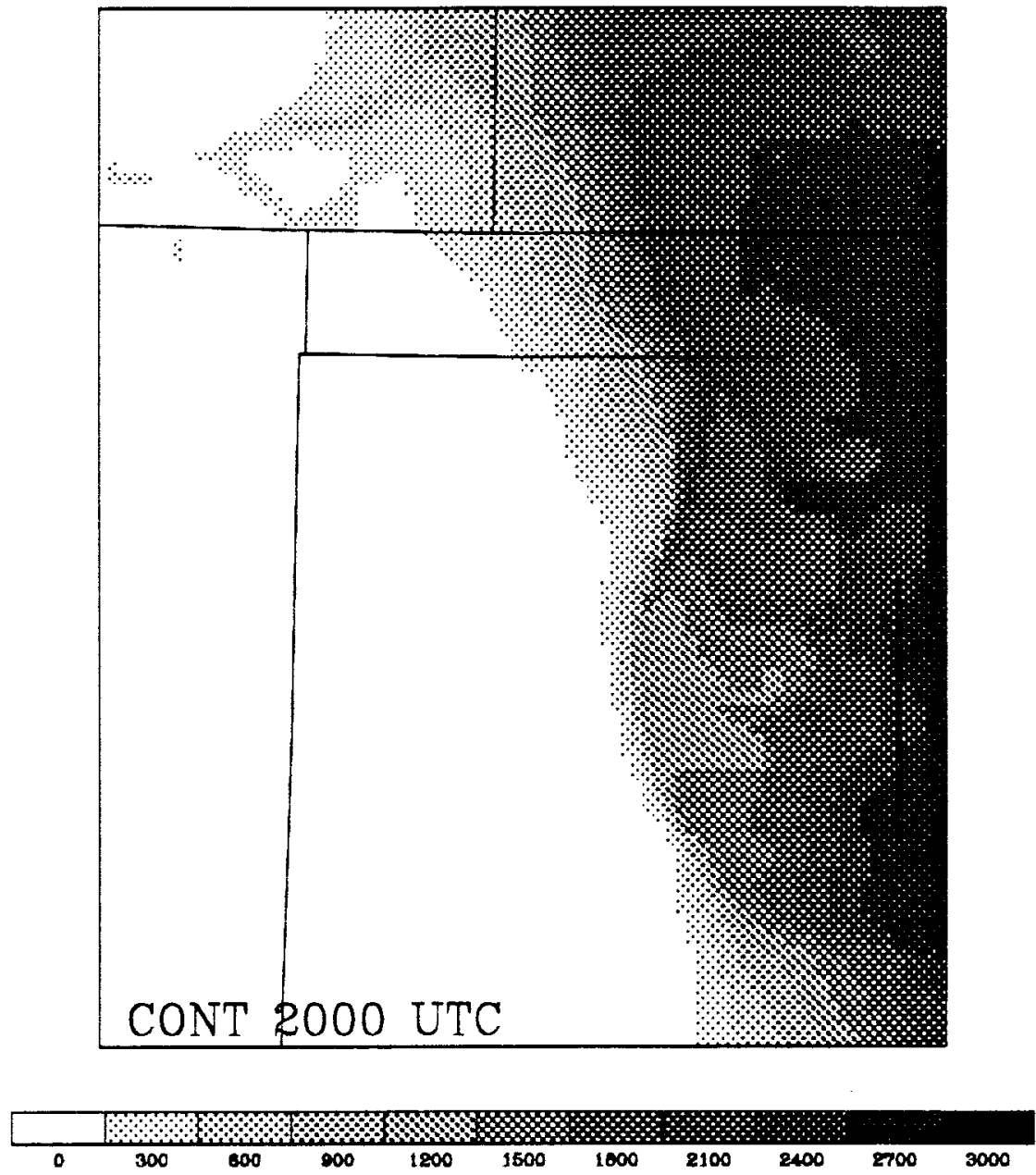

FIG. 11. CAPE $\left(\mathrm{J} \mathrm{kg}^{-1}\right)$ for the control simulation at 2000 UTC. Using model profiles, CAPE is computed following definition given by Bluestein and Parker (1993). The values were calculated based on an average of the lowest $1 \mathrm{~km}$ of data. Values on scale represent the minimum value of the corresponding shade.

SREH undergoes significant gradients along portions of the dryline. Large areas east of the dryline had SREH values greater than or equal to $100 \mathrm{~m}^{2} \mathrm{~s}^{-2}$, and an area of maximum SREH exceeding $200 \mathrm{~m}^{2} \mathrm{~s}^{-2}$ occurred near Childress. This was a result of the easterly winds induced by the strong virtual potential temperature gradient around the edge of the moist soil patch. This highlights the importance of the soil moisture effect on the localization of low-level wind shear.

The fine grid used in the simulation was not of high enough resolution to explicitly resolve convection. Nevertheless, it is interesting that the model produced local regions of grid-scale water saturation due to lifting of moisture at the dryline. The areas where precipitation was produced corresponded to the same areas where convective cells were indicated by NWS radar summary charts.

These areas of resolved precipitation, shown in detail in Shaw (1995), are a result of the pressure and buoy- ancy forces causing a vertical acceleration as in real convection. These precipitation features in our simulation are related to but distinct from parameterized subgrid convection as developed for regional and mesoscale models, since our model configuration did not employ any convective parameterizations. These precipitation fields are broadly comparable to results of Lakhtakia and Warner (1987), who employed a subgrid convective parameterization to simulate formation of "lid-edge" precipitation using The Pennsylvania State University MM4 regional model. Due to the much finer grid resolution and nonhydrostatic dynamics in the present case, precipitation is much more localized and produces more realistic low-level cold pool boundary layer features than in the former study.

\section{Sensitivity tests}

Other simulations were run to test the dryline and prestorm environment response to variations in the soil 


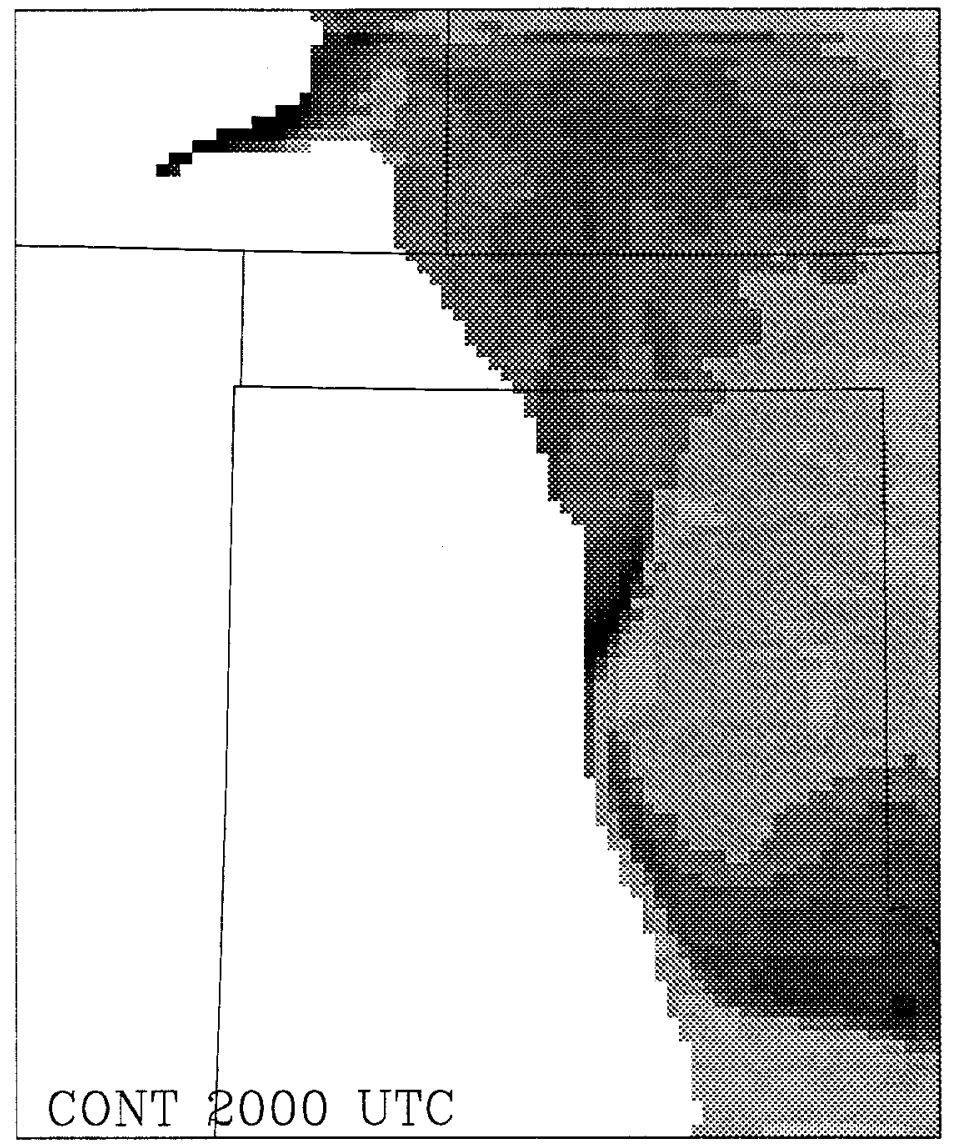

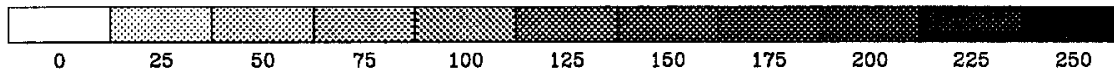

FIG. 12. Storm-relative environmental helicity $\left(\mathrm{m}^{2} \mathrm{~s}^{-2}\right)$ at $2000 \mathrm{UTC}$ from the control simulation. Using model profiles, SREH is computed following definition given by Bluestein and Parker (1993). SREH is plotted only at points where the CAPE equals or exceeds $500 \mathrm{~J} \mathrm{~kg}^{-1}$. Values on the scale represent the minimum value for the corresponding shade.

moisture and vegetation patterns. All of the sensitivity tests are detailed in Shaw (1995). This paper presents selected results from the most significant sensitivity test, a simulation that used the same model configuration as the control run except for the initialization of soil moisture with a constant dry value. We called this test the "homogeneous-dry" (HOMD) simulation.

Figure 13 illustrates how the dryline evolved differently in the control and HOMD simulations. In both runs, the moisture gradient gradually formed and moved east until 0000 UTC. After 2100 UTC, the gradient sharpened dramatically in the control simulation and moistening of the CBL east of the dryline continued. This continued moistening was in sharp contrast to the drying, which occurred in the HOMD simulation. The moisture gradient in the HOMD advanced farther east along this transect than in the control simulation and was of much weaker magnitude. In fact, the gradient was weak enough that one could argue that a classical dryline did not form.

One additional point of interest is the double peak of moisture in the HOMD simulation. Both of these gradient peaks were collocated with a zone of convergence. This multiple gradient feature has been observed in several cases (Hane et al. 1993) and may be a manifestation of the breakdown of a single vertical circulation east of the dryline into multiple circulations.

An analysis of virtual potential temperature from the lowest model grid level from the control run and the HOMD run is shown in Fig. 14. This figure clearly supports the hypothesis that an east to west gradient of decreasing soil moisture enhances the virtual potential temperature gradient. The lack of a soil moisture gradient in the HOMD run led to a much more uniform distribution of surface heat fluxes and a weaker eastwest virtual potential temperature gradient than the con- 


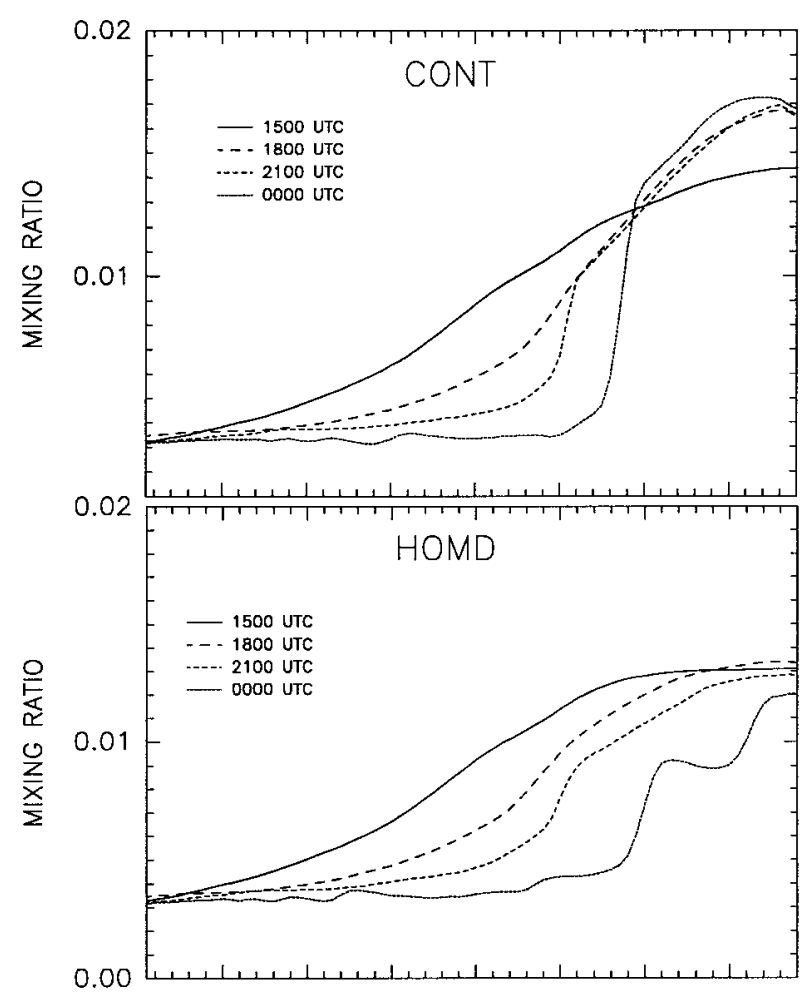

FIG. 13. West-to-east profile of surface (i.e., lowest model grid point) mixing ratio on grid 3 at 1500,1800, 2100, and 0000 UTC for each of the simulations. Profiles are taken at same latitude as P-3 transect in the eastern Texas panhandle (Hane et al. 1993), averaging over six points in the north-south direction. Here one horizontal grid interval equals $5 \mathrm{~km}$.

trol run. This, in turn, allowed the moist air in the eastern Texas panhandle to mix out much more rapidly, allowing the dryline to penetrate farther east with a slightly faster eastward movement. This is consistent with the notion that the net dryline motion is a result of the balance between the westward density current-like movement and the eastward movement due to advection by the prevailing westerly shear (Ziegler et al. 1995). Since the virtual potential temperature gradient was weaker in the HOMD case, the density current component was weaker, thus allowing the advective component to have more of an impact during the afternoon.

Both simulations were compared to observations using a statistical approach. Following the methodology utilized by Keyser and Anthes (1977) and outlined by Pielke (1984), values of model rms error $(E)$, unbiased rms error $\left(E_{\mathrm{ub}}\right)$, and the standard deviation of the observations $\left(\sigma_{\text {obs }}\right)$ and closest model grid points $(\sigma)$ were computed for each hour of the control simulation. Six available observation sites (two conventional, four PAM-II sites) were used for the analysis. Stations were located on both sides of the afternoon dryline. It should also be noted that the PAM-II stations used for verification were not used in the initialization of the simulations.

The skill indicator ratios and the model bias from
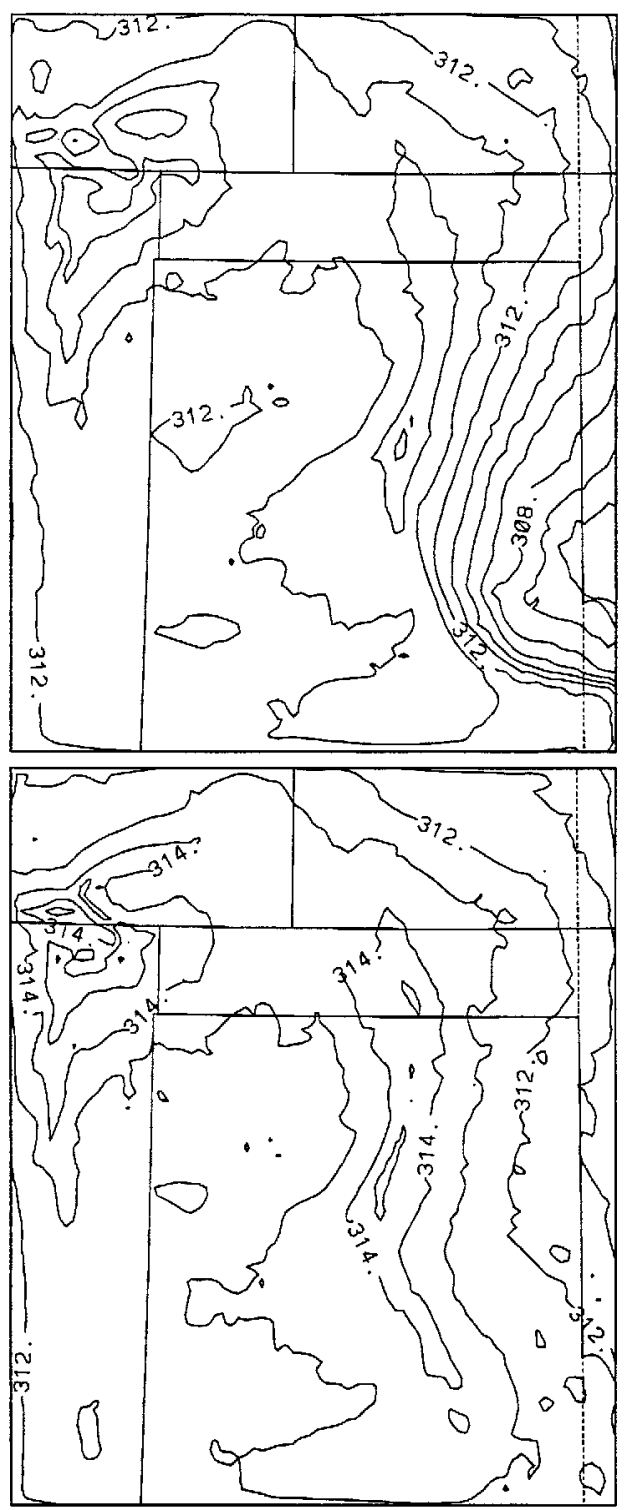

FIG. 14. Surface virtual potential temperature analysis (K) at 2000 UTC from the CONT (top) and HOMD (bottom) runs. Contour interval of $1 \mathrm{~K}$.

both simulations for surface potential temperature and mixing ratio are shown in Tables 2 and 3, respectively. For a model to have skill, $\sigma / \sigma_{\text {obs }}$ should be near unity, while $E / \sigma_{\mathrm{obs}}$ and $E_{\mathrm{ub}} / \sigma_{\mathrm{obs}}$ should each be less than one. The smaller the latter two ratios are, the better the skill indicated.

TABLE 2. Ratios indicating skill and bias of the control (CONT) and HOMD simulations for six observations of surface potential temperature. The values shown are the mean values for all hours.

\begin{tabular}{lcccc}
\hline \hline Run & $\sigma / \sigma_{\text {obs }}$ & $E / \sigma_{\text {obs }}$ & $E_{\text {ub }} / \sigma_{\text {obs }}$ & Bias $(\mathrm{K})$ \\
\hline CONT & 1.13 & 0.61 & 0.54 & -0.62 \\
HOMD & 2.67 & 0.80 & 0.66 & 0.64 \\
\hline
\end{tabular}


TABLE 3. Same as Table 2 but for surface mixing ratio.

\begin{tabular}{ccccc}
\hline \hline Run & $\sigma / \sigma_{\text {obs }}$ & $E / \sigma_{\text {obs }}$ & $E_{\mathrm{ub}} / \sigma_{\text {obs }}$ & Bias $\left(\mathrm{g} \mathrm{kg}^{-1}\right)$ \\
\hline CONT & 1.14 & 0.47 & 0.37 & 0.59 \\
HOMD & 1.33 & 0.46 & 0.36 & -0.61 \\
\hline
\end{tabular}

It is quite apparent from these tables that the inclusion of a realistic variable soil moisture made a significant difference on the skill of the simulations. The HOMD simulation had significantly less skill based on the ratio of the standard deviations, especially in the potential temperature forecasts.

\section{Summary and conclusions}

Several new approaches and results are demonstrated in this study. First, three-dimensional simulations of the dryline environment at rather high resolution employing a realistic initialization (including soil moisture and vegetation) provide more detailed insight into the evolution of the dryline environment than ever before. Second, the validation of the control simulation with PAM-II observations, aircraft observations, and M-CLASS soundings including the interpretation of Bowen ratio tendency with saturation-point analyses lends credibility to the simulation results.

The results document the realistic simulation of dryline formation and movement; sharp across-dryline gradients of moisture, temperature, horizontal winds, and vertical motion [comparable to Ziegler et al. (1995) but much larger than in previous studies]; irregularities of the dryline in the north-south direction; and the presence of convergence bands in the boundary layer west and east of the dryline itself. Additionally, the results show a direct, positive correlation between the soil moisture pattern and the regional sensible and latent heat flux patterns. Furthermore, the results show that these patterns play a significant role in the formation of large gradients in the local structure of convective instability and helicity. Thus, it is concluded that the prediction of the convective storm mode and the ability of numerical models to accurately forecast such activity along the dryline is directly tied to the ability to simulate the detailed dryline morphology. This, in turn, may very well be tied to our ability to accurately represent the soil moisture and vegetation conditions at spatial resolutions comparable to or better than this study.

Finally, the sensitivity tests show the impact that a change in the soil moisture pattern has on the resulting dryline formation. The apparently more accurate representation by the control run suggests the value of including such information in operational forecast models. Additionally, the response of the boundary layer horizontal virtual potential temperature gradient to the soil moisture gradient and the resulting dryline structure validates the hypothesis that kinematic frontogenetic forcing is key to the formation and sustenance of the very large atmospheric moisture gradients found along drylines. The soil moisture gradient appears to be a key mechanism for generation of solenoidal forcing critical to the kinematic frontogenesis process. Additionally, the moist soil east of the dryline provides a source of moisture replenishment for the boundary layer that offsets the drying effect of warm, dry air west of the dryline being mixed down to the surface at the convergence zone. This is analogous to large-scale, synoptically forced cold fronts, where warm advection at the surface ahead of the cold front aids in maintaining the strong temperature gradient. In the case of the dryline, the proximity of the moist soil to the east allows moisture transport to the dryline zone in timescales much shorter than if the only moisture source was farther away (e.g., the Gulf of Mexico). This may be one of the reasons drylines (in contrast to strong cold fronts) are able to develop intense gradients and dissipate on a daily basis during synoptically quiescent periods.

Based on these results, it appears likely that there is a relationship between the land surface conditions and dryline formation and evolution. This leads to an interesting question regarding cause and effect, since while the dryline is apparently affected by land surface, the land surface is also affected by the temperature, humidity, and precipitation regimes associated with the dryline. A suggested future study would be to couple RAMS or a similar regional model with an ecosystem dynamics model and perform seasonal or longer-term experiments to see how the vegetation coverage and weather patterns interact.

Additionally, future studies could involve sensitivity simulations using more detailed precipitation analyses [e.g., perhaps derived from the WSR-88D radar network; or from satellite; Jones (1996)] and a realistic variable soil-type database for improved analysis of soil moisture. Ultimately, simulations should be run in a quasi-operational mode using these improved initialization techniques and the results compared to those of the current suite of operational regional models being used by civilian and military weather centers.

As new methods and data are incorporated in specifying the land surface conditions, our understanding of their effects on the atmosphere should increase. This will have a direct benefit for new operational mesoscale models, thus improving our ability to forecast short term mesoscale weather events.

Acknowledgments. We would like to thank all of the people who assisted with the model configuration and data acquisition. Without the efforts of Jeff Copeland, John Lee, Bob Walko, Tom Chase, Cathy Finley, and Louis Grasso, this research could not have been completed. Additional thanks are extended to Dallas McDonald for her efforts in helping prepare the manuscript. Ray Arritt also provided invaluable comments and suggestions. We would also like to thank the anon- 
ymous reviewers for their diligent and thoughtful critiques.

This research is extracted from the lead author's (BLS) M.S. thesis from Colorado State University and he would like to acknowledge the contribution and guidance provided by his advisor, Roger Pielke, and his committee members, Richard Johnson, William Lauenroth, and Conrad Ziegler. The lead author was principally supported by the Air Force Institute of Technology. Additional financial support was received from National Science Foundation (NSF) Grant ATM-9306754 and United States Geological Survey (USGS) Grant 143494-A-1275. Observational data for this study were obtained from the NOAA/National Severe Storms Laboratory and from the National Center for Atmospheric Research (NCAR), which is partially supported by the NSF. The PAM network in the 1991 field project was provided by the NCAR Atmospheric Technology Division with partial support from the National Aeronautics and Space Administration.

\section{REFERENCES}

Anthes, R. A., 1984: Enhancements of convective precipitation by mesoscale variations in vegetative covering in semi-arid regions. J. Climate Appl. Meteor., 23, 541-554.

— , Y. H. Kuo, S. G. Benjamin, and Y.-F. Li, 1982: The evolution of the mesoscale environment of severe local storms: Preliminary modeling results. Mon. Wea. Rev., 110, 1187-1213.

Avissar, R., and R. A. Pielke, 1989: A parameterization of heterogeneous land surfaces for atmospheric numerical models and its impact on regional meteorology. Mon. Wea. Rev., 117, 21132136.

Benjamin, S. G., 1986: Some effects of surface heating and topography on the regional severe storm environment. Mon. Wea. Rev., 114, 307-343.

— topography on the regional severe storm environment. Part I: 3-D simulations. Mon. Wea. Rev., 114, 330-343.

Betts, A. K., 1982: Saturation point analysis of moist convective overturning. J. Atmos. Sci., 39, 1484-1505.

_ 1984: Boundary layer thermodynamics of a High Plains severe storm. Mon. Wea. Rev., 112, 2199-2211.

Bluestein, H. B., and S. S. Parker, 1993: Modes of isolated, severe convective storm formation along the dryline. Mon. Wea. Rev. 121, 1354-1372.

Bonan, G. B., D. Pollard, and S. L. Thompson, 1993: Influence of subgrid-scale heterogeneity in leaf area index, stomatal resistance, and soil moisture on grid-scale land-atmospheric interactions. J. Climate, 6, 1882-1897.

Brock, F., G. Saum, and S. Semmer, 1986: Portable Automated Mesonet II. J. Atmos. Oceanic Technol., 3, 373-582.

Chang, J.-T., and P. J. Wetzel, 1991: Effects of spatial variations of soil moisture and vegetation on the evolution of a prestorm environment: A case study. Mon. Wea. Rev., 119, 1368-1390.

Cotton, W. R., G. Thompson, and P. W. Mielke Jr., 1994: Real-time mesoscale prediction on workstations. Bull. Amer. Meteor. Soc., $\mathbf{7 5}, 349-362$.

Cram, J. M., and R. A. Pielke, 1987: The importance of synoptic forcing and mesoscale terrain to a numerical simulation of an orographically-induced system. Proc. Third AMS Conf. on Mesoscale Processes, Vancouver, BC, Canada, Amer. Meteor. Soc. 118-119.

— - , and W. R. Cotton, 1992: Numerical simulation and anal- ysis of a pre-frontal squall line. Part I: Observations and basic simulation results. J. Atmos. Sci., 49, 189-208.

Dickinson, R. E., A. Henderson-Sellers, P. J. Kennedy, and M. F. Wilson, 1986: Biosphere-atmosphere transfer scheme for the NCAR Community Climate Model. Tech. Rep. NCAR/TN275+STR, NCAR, 69 pp. [Available from NSSL, 1313 Halley Circle, Norman, OK 73069.]

Dodd, A. V., 1965: Dew point distribution in the contiguous United States. Mon. Wea. Rev., 93, 113-122.

Estoque, M. A., 1962: The sea-breeze as a function of the prevailing synoptic situation. J. Atmos. Sci., 19, 244-250.

Garrett, A. J., 1982: A parameter study of interactions between convective clouds, the boundary layer, and a forest surface. Mon. Wea. Rev., 110, 1041-1058.

Grasso, L. D., 1996: Numerical simulation of the 15 May and 26 April 1991 thunderstorms. Colorado State University Department of Atmospheric Sciences Paper 596, 151 pp. [Available from Colorado State University, Fort Collins, CO 80523.]

Hane, C. E., C. L. Ziegler, and H. B. Bluestein, 1993: Investigation of the dryline and convective storms initiated along the dryline: Field experiments during COPS-91. Bull. Amer. Meteor. Soc., 74, 2133-2145.

Jones, A. S., 1996: The use of satellite-derived heterogeneous surface soil moisture for numerical weather prediction. Ph.D. dissertation, Colorado State University, 491 pp. [Available from Colorado State University, Fort Collins, CO 80523.]

Keyser, D., and R. A. Anthes, 1977: The applicability of a mixedlayer model of the planetary boundary layer to real-data forecasting. Mon. Wea. Rev., 105, 1351-1371.

Koch, S. E., and J. McCarthy, 1982: The evolution of an Oklahoma dryline. Part II: Boundary-layer forcing of mesoconvective systems. J. Atmos. Sci., 39, 237-257.

Kosta, R. D., and M. J. Suarez, 1992: A comparative analysis of two land surface heterogeneity representations. J. Climate, 5, 13791390.

Lakhtakia, M. N., and T. T. Warner, 1987: A real-data numerical study of the development of precipitation along the edge of an elevated mixed layer. Mon. Wea. Rev., 115, 156-168.

Lanicci, J. M., T. N. Carlson, and T. T. Warner, 1987: Sensitivity of the Great Plains severe-storm environment to soil-moisture distribution. Mon. Wea. Rev., 115, 2660-2673.

Lee, T. J., 1992: The impact of vegetation on the atmospheric boundary layer and convective storms. Colorado State University Department of Atmospheric Sciences Paper 509, 137 pp. [Available from Colorado State University, Fort Collins, CO 80523.]

Lemeur, R., and N. J. Rosenberg, 1979: Simulating the quality and quantity of short wave radiation within and above canopies. Comparison of Forest Water and Energy Exchange Models, S. Halldin, Ed., International Society for Ecological Modelling, 77100.

Li, B., and R. Avissar, 1994: The impact of spatial variability of landsurface heat fluxes. J. Climate, 7, 527-537.

Lyons, W. A., D. A. Moon, C. S. Keen, J. A. Schuh, R. A. Pielke, W. R. Cotton, and R. W. Arritt, 1988: Providing operational guidance for the development of sea breeze thunderstorms at the Kennedy Space Center: An experiment using a mesoscale numerical model. Proc. 15th Conf. on Severe Local Storms, Baltimore, MD, Amer. Meteor. Soc., J125-J132.

Mahrt, L., 1991: Boundary layer moisture regimes. Quart. J. Roy. Meteor. Soc., 117, 151-176.

McCumber, M. C., and R. A. Pielke, 1981: Simulation of the effects of surface fluxes of heat and moisture in a mesoscale numerical model. Part I: Soil layer. J. Geophy. Res., 86 (C10), 9929-9938.

McGinley, J. A., and Y. K. Sasaki, 1975: The role of symmetric instabilities in thunderstorm development on drylines. Preprints, Ninth Conf. on Severe Local Storms, Boston, MA, Amer. Meteor. Soc., 173-180.

McGuire, E. L., 1962: The vertical structure of three drylines as revealed by aircraft traverses. National Severe Storms Project 
Rep., 7, 11 pp. [Available from NCAR, P.O. Box 3000, Boulder, CO 80307.]

National Severe Storms Project Staff Members, 1963: Environmental and thunderstorm structures as shown by National Severe Storms Project observations in spring 1960 and 1961. Mon. Wea. Rev., 91, 271-292.

Nicholls, M. E., R. A. Pielke, J. L. Eastman, C. A. Finley, W. A. Lyons, C. J. Tremback, R. L. Walko, and W. R. Cotton, 1995: Applications of the RAMS numerical model to dispersion over urban areas. Wind Climate in Cities, J. E. Cermak et al., Eds., Kluwer Academic Publishers, 703-732.

Ogura, Y., and Y. Chen, 1977: A life history of an intense mesoscale convective storm in Oklahoma. J. Atmos. Sci., 34, 1458-1476.

Parsons, D. B., M. A. Shapiro, R. M. Hardesty, and R. J. Zamora, 1991: The finescale structure of a west Texas dryline. Mon. Wea. Rev., 119, 1242-1258.

Pielke, R. A., 1974: A three-dimensional numerical model of the seabreezes over south Florida. Mon. Wea. Rev., 102, 115-139.

- 1984: Mesoscale Meteorological Modeling. Academic Press, $612 \mathrm{pp}$.

—, and M. Segal, 1986: Mesoscale circulations forced by differential terrain heating. Mesoscale Meteorology and Forecasting, P. S. Ray, Ed., Amer. Meteor. Soc., 516-548.

_ , and R. Avissar, 1990: Influence of landscape structure on local and regional climate. Landscape Ecol., 4, 133-155.

—, and Coauthors, 1992: A comprehensive meteorological modeling system-RAMS. Meteor. Atmos. Phys., 49, 69-91.

— T. J. Lee, J. H. Copeland, J. L. Eastman, C. L. Ziegler, and C. A. Finley, 1997: Use of USGS-provided data to improve weather and climate simulations. Ecol. Appl., in press.

Pitman, A. J., 1994: Assessing the sensitivity of a land-surface scheme to the parameter values using a single column model. J. Climate, 7, 1856-1869.

Pleim, J. E., and A. Xiu, 1995: Development and testing of a surface flux and planetary boundary layer model for application in mesoscale models. J. Appl. Meteor., 34, 16-32.

Rust, W. D., R. P. Davies-Jones, D. W. Burgess, R. A. Maddox, L. C. Showell, T. C. Marshall, and D. K. Lauritsen, 1990: Testing a mobile version of a Cross-chain Loran Atmospheric (M-CLASS) Sounding System. Bull. Amer. Meteor. Soc., 71, 173-180.

Schaefer, J. T., 1986: The dryline. Mesoscale Meteorology and Forecasting, P. S. Ray, Ed., Amer. Meteor. Soc., 549-570.
Segal, M., and R. W. Arritt, 1992: Nonclassical mesoscale circulations caused by surface sensible heat-flux gradients. Bull. Amer. Meteor. Soc., 73, 1593-1604.

,-- C. Clark, R. Rabin, and J. Brown, 1995: Scaling evaluation of the effect of surface characteristics on potential for deep convection over uniform terrain. Mon. Wea. Rev., 123, 383400.

Shaw, B. L., 1995: The effect of soil moisture and vegetation heterogeneity on a Great Plains dryline: A numerical study. Colorado State University Department of Atmospheric Sciences Paper 576, 93 pp. [Available from Colorado State University, Fort Collins, CO 80523.]

Smith, C. B., M. N. Lakhtakia, W. J. Capehart, and T. N. Carlson, 1994: Initialization of soil-water content in regional-scale atmospheric prediction models. Bull. Amer. Meteor. Soc., 75, 585593.

Stull, R. B., 1988: An Introduction to Boundary Layer Meteorology. Kluwer Academic Publishers, 666 pp.

Sun, W.-Y., and Y. Ogura, 1979: Boundary layer forcing as a possible trigger to a squall-line formation. J. Atmos. Sci., 36, 235-254.

— dryline. J. Atmos. Sci., 49, 1606-1618.

Tremback, C. J., and R. Kessler, 1985: A surface temperature and moisture parameterization for use in mesoscale models. Proc. Seventh Conf. on Numerical Weather Prediction, Boston, MA, Amer. Meteor. Soc., 355-358.

U.S. Department of Commerce and U.S. Department of Agriculture (USDOC/USDA), 1991: Weekly Weather and Crop Bulletin, 78, p. 19.

Wallace, J. M., and P. V. Hobbs, 1977: Atmospheric Science: An Introductory Survey. Academic Press, $465 \mathrm{pp}$.

Wetzel, P. J., and J.-T. Chang, 1988: Evapotranspiration from nonuniform surfaces: A first approach for short-term numerical weather prediction. Mon. Wea. Rev., 116, 600-621.

Yan, H., and R. A. Anthes, 1988: The effect of variations in surface moisture on mesoscale circulations. Mon. Wea. Rev., 116, 192208.

Zhang, D., and R. A. Anthes, 1982: A high resolution model of the planetary boundary layer-sensitivity tests and comparisons with SESAME-79 data. J. Appl. Meteor., 21, 1594-1609.

Ziegler, C. L., and C. E. Hane, 1993: An observational study of the dryline. Mon. Wea. Rev., 121, 1134-1151.

- W. J. Martin, R. A. Pielke, and R. L. Walko, 1995: A modeling study of the dryline. J. Atmos. Sci., 52, 263-285. 